Arq. Bras. Med. Vet. Zootec., v.66, n.2, p.360-366, 2014

\title{
Eficiência de lagoas de polimento no pós-tratamento de reator UASB no tratamento de águas residuárias de suinocultura
}

\author{
[Efficiency of a polishing pond for the post-treatment of the effluent from UASB \\ reactor treating swine wastewater] \\ A.C.A. Pinto ${ }^{1}$, L.S. Rodrigues ${ }^{2 *}$, P.R. Oliveira ${ }^{2}$, M.V. Sperling ${ }^{2}$, C.M. Crisóstomo ${ }^{3}$, I.J. Silva ${ }^{2}$ \\ ${ }^{1}$ Aluna de pós-graduação - Universidade Federal de Minas Gerais - UFMG - Belo Horizonte, MG \\ ${ }^{2}$ Universidade Federal de Minas Gerais - UFMG - Belo Horizonte, MG \\ ${ }^{3}$ Médica veterinária autônoma - Belo Horizonte, MG
}

\section{RESUMO}

Avaliou-se o desempenho de um sistema de lagoas seriadas que recebeu efluentes de reator UASB, no tratamento de águas residuárias de suinocultura. O sistema foi composto de reator anaeróbio de chicanas (RAC), reator UASB, em escala real, e uma série de lagoas (uma lagoa facultativa e três de maturação), em escala piloto. As análises físico-químicas realizadas foram: $\mathrm{pH}$, demanda bioquímica de oxigênio (DBO), demanda química de oxigênio (DQO), sólidos suspensos totais (SST), sólidos suspensos voláteis (SSV), nitrogênio amoniacal (N-am.), fósforo total (Pt), coliformes totais (CT) e Escherichia coli (EC). As lagoas de pós-tratamento contribuíram eficientemente para remoção de nutrientes, matéria orgânica e sólidos, fornecendo um efluente com qualidade para o reuso agrícola ou lançamento em corpos d'água.

Palavras-chave: suinocultura, lagoas de pós-tratamento, reator UASB

\begin{abstract}
The performance of a post-treatment pond for treating swine wastewater from an UASB reactor was evaluated. The system was assembled with an anaerobic baffle reactor (RAC), followed by an UASB reactor (UASB) on a real scale, and a post-treatment pond on a demonstration scale. The following parameters were analyzed: $\mathrm{pH}$, biochemical oxygen demand (BOD), chemical oxygen demand (COD), total suspended solids (TSS), volatile suspended solids (VSS), ammonia nitrogen (N-am.), total phosphorus (Pt), total coliforms (CT) and Escherichia coli (E coli.). The post-treatment lagoons contributed efficiently to remove nutrients, organic matter and solids, providing an effluent quality for agricultural reuse or discharge into a body of water.
\end{abstract}

Keywords: swine wastewater, post-treatment pond, UASB reactor

\section{INTRODUÇÃO}

A suinocultura constitui uma das cadeias produtivas mais bem estruturadas do agronegócio brasileiro, compreendendo o terceiro maior rebanho mundial, porém sua exploração é considerada pelos órgãos de controle ambiental como uma atividade potencialmente causadora de degradação ambiental, sendo enquadrada como de grande potencial poluidor (Palhares e Calijuri, 2006).
As águas residuárias de suinocultura apresentam altas concentrações de sólidos suspensos orgânicos, provocando impactos ambientais acentuados em várias regiões do Brasil, bem como em outros países. A suinocultura no Brasil vem destacando-se no cenário do comércio internacional pela sua elevada qualidade técnica e produtividade, porém com este elevado desenvolvimento também cresceram os problemas decorrentes da disposição dos dejetos (Ishizuka, 2003).

Recebido em 18 de maio de 2012

Aceito em 11 de novembro de 2013

*Autor para correspondência (corresponding author)

E-mail:lsantosrodrigues@gmail.com 
Uma das maneiras de tratar águas residuárias geradas em suinoculturas é por meio da utilização do reator anaeróbio de manta de lodo (UASB), o qual pode ser construído e operado de forma a minimizar os custos do tratamento com baixa produção de sólidos. Esse tipo de reator, como os demais sistemas anaeróbios, produz como subproduto o biogás, que pode ser utilizado como fonte de energia alternativa em motores de combustão interna. O lodo anaeróbio excedente pode ser utilizado como fertilizante, e o líquido que sai do reator (efluente) pode ser aplicado no solo para fertirrigação de culturas agrícolas (Campos et al., 2006).

Apesar das suas grandes vantagens, os reatores anaeróbios dificilmente produzem efluentes que atendam aos padrões estabelecidos pela legislação ambiental. Torna-se de grande importância, portanto, o pós-tratamento dos efluentes dos reatores anaeróbios, como uma forma de adequar o efluente tratado aos requisitos da legislação ambiental e propiciar a proteção dos corpos d'água receptores dos lançamentos dos esgotos (Carmo et al., 2004).

Entre as alternativas de pós-tratamento, destacase o uso das lagoas de polimento, pelo fato de manterem em todo o sistema a simplicidade conceitual já assumida para os reatores anaeróbios, além de oferecerem condições favoráveis para remoção de nutrientes e patógenos (Sperling, 2002).

Diante disto, este trabalho tem como objetivo avaliar a eficiência na remoção de matéria orgânica, nutrientes e patógenos em efluentes de suinocultura, com um sistema anaeróbio de dois estágios, constituído de reator anaeróbio compartimentado (RAC) e reator UASB, em escala real, seguidos de uma lagoa facultativa e três de maturação, em escala piloto.

\section{MATERIAL E MÉTODOS}

O trabalho foi realizado junto às instalações da suinocultura da Fazenda Experimental da Escola de Veterinária da Universidade Federal de Minas Gerais (UFMG), localizada no município de Igarapé, Minas Gerais.

O sistema de tratamento experimental foi composto por uma série de lagoas de póstratamento, sendo uma facultativa (LF) e três de maturação (LM1, LM2 e LM3), que recebiam efluentes de um sistema em escala real composto por peneira estática, reator anaeróbio de chicanas (RAC) e reator UASB, por meio de bombeamento.

A alimentação do sistema experimental foi realizada a partir do efluente do reator UASB, formado por uma caixa de armazenamento com capacidade de $1 \mathrm{~m}^{3}$, por uma lagoa facultativa de dimensões $2,00 \times 4,00 \times 1,10 \mathrm{~m}$, e por três lagoas de maturação em série de dimensões 3,00 x $0,60 \mathrm{~m}$ cada, operadas com a profundidade de $0,4 \mathrm{~m}$.

As medições da vazão no RAC e no reator UASB foram realizadas durante todo o período de higienização da manhã, enquanto nas lagoas a vazão média foi medida em função do tempo de funcionamento e da vazão da bomba centrífuga.

O programa de monitoramento do sistema de tratamento teve duração de sete meses, realizado por meio de análises físico-químicas e bacteriológicas. Os parâmetros avaliados foram: pH, DBO, DQO, sólidos suspensos totais (SST), sólidos suspensos voláteis (SSV), nitrogênio amoniacal (N-am.), fósforo total (Pt), coliformes totais (CT) e Escherichia coli. As amostras foram coletadas semanalmente no afluente e no efluente do RAC, do reator UASB, da LF e das três lagoas de maturação (LM1, LM2, LM3).

As análises físico-químicas e bacteriológicas foram realizadas no Laboratório de Saneamento Ambiental da Escola de Veterinária, conforme descrito no Standard Methods for Examination of Water and Wastewater (APHA/ AWWA /WEF, 1998).

Foram calculadas a eficiência de remoção de cada unidade de tratamento e a global da estação de tratamento de esgotos (ETE), considerando-se o afluente ao RAC e o efluente da última lagoa de maturação.

\section{RESULTADOS E DISCUSSÃO}

Na Tab. 1, são apresentados os valores médios das concentrações afluentes e efluentes das diversas unidades de tratamento para os parâmetros DBO, DQO, SST, SSV, N-am., Pt, CT e E. coli, e na Tab. 2 os valores médios de eficiência. 
Tabela 1. Média e desvio-padrão (DP) dos parâmetros de avaliação do afluente e dos efluentes do RAC, do reator UASB, da lagoa facultativa e da série de lagoas de maturação

\begin{tabular}{|c|c|c|c|c|c|}
\hline \multirow[b]{2}{*}{ Parâmetro } & \multicolumn{5}{|c|}{ Resultados } \\
\hline & Afluente & RAC & UASB & LF & $\begin{array}{l}\text { Lagoas } \\
\text { seriadas }\end{array}$ \\
\hline $\begin{array}{l}\text { Demanda bioquímica de oxigênio } \\
\qquad\left(\mathrm{mg} \mathrm{L}^{-1}\right)\end{array}$ & $5321 \pm 3405$ & $970 \pm 1233$ & $131 \pm 155$ & $61 \pm 38$ & $87 \pm 60$ \\
\hline $\begin{array}{l}\text { Demanda química de oxigênio } \\
\qquad\left(\mathrm{mg} \mathrm{L}^{-1}\right)\end{array}$ & $16074 \pm 6932$ & $2913 \pm 1514$ & $611 \pm 223$ & $524 \pm 314$ & $505 \pm 334$ \\
\hline $\begin{array}{c}\text { Sólidos suspensos totais } \\
\left(\mathrm{mg} \mathrm{L}^{-1}\right)\end{array}$ & $5387 \pm 2409$ & $1030 \pm 752$ & $138 \pm 67$ & $107 \pm 66$ & $166 \pm 125$ \\
\hline $\begin{array}{l}\text { Sólidos suspensos voláteis } \\
\qquad\left(\mathrm{mg} \mathrm{L}^{-1}\right)\end{array}$ & $4700 \pm 2117$ & $879 \pm 606$ & $134 \pm 65$ & $106 \pm 65$ & $165 \pm 124$ \\
\hline $\begin{array}{c}\text { Nitrogênio amoniacal } \\
\left(\mathrm{mg} \mathrm{L}^{-1}\right)\end{array}$ & $202 \pm 131$ & $315 \pm 188$ & $309 \pm 166$ & $247 \pm 154$ & $140 \pm 129$ \\
\hline Fósforo total $\left(\mathrm{mg} \mathrm{L}^{-1}\right)$ & $100 \pm 60$ & $64 \pm 34$ & $48 \pm 25$ & $29 \pm 14$ & $18 \pm 6$ \\
\hline $\begin{array}{l}\text { Coliformes termotolerantes } \\
\left(\text { NMP } 100 \mathrm{~mL}^{-1}\right)\end{array}$ & $3 \mathrm{E}+9 \pm 1 \mathrm{E}+10$ & $5 \mathrm{E}+7 \pm 8 \mathrm{E}+8$ & $3 \mathrm{E}+6 \pm 5 \mathrm{E} 6$ & $6 \mathrm{E}+5 \pm 4 \mathrm{E}+6$ & $2 \mathrm{E}+4 \pm 2 \mathrm{E}+5$ \\
\hline $\begin{array}{l}\text { Escherichia coli } \\
\left(\mathrm{NMP} 100 \mathrm{~mL}^{-1}\right)\end{array}$ & $2 \mathrm{E}+9 \pm 8 \mathrm{E}+9$ & $3 \mathrm{E}+7 \pm 7 \mathrm{E}+8$ & $2 \mathrm{E}+6 \pm 5 \mathrm{E}+6$ & $2 \mathrm{E}+5 \pm 1 \mathrm{E}+6$ & $4 \mathrm{E}+3 \pm 2 \mathrm{E}+4$ \\
\hline
\end{tabular}

Tabela 2. Eficiência média de remoção de matéria orgânica, sólidos, nutrientes e coliformes no RAC, no reator UASB, na lagoa facultativa e na série de lagoas de maturação durante o período experimental.

\begin{tabular}{lccccc}
\hline \multicolumn{1}{c}{ Parâmetro } & \multicolumn{3}{c}{ Eficiência em cada unidade (\%) } & \multirow{2}{*}{$\begin{array}{c}\text { Eficiência } \\
\text { global }(\%)\end{array}$} \\
\cline { 2 - 5 } & RAC & UASB & LF & Série das LM & \\
\cline { 2 - 5 } Demanda bioquímica de oxigênio & 81,8 & 86,5 & 53,4 & $-42,6$ & 98,4 \\
Demanda química de oxigênio & 81,9 & 79,0 & 14,2 & 3,6 & 96,9 \\
Sólidos suspensos totais & 80,9 & 86,6 & 22,5 & $-55,1$ & 96,6 \\
Sólidos suspensos voláteis & 81,3 & 84,8 & 20,9 & $-55,7$ & 96,5 \\
Nitrogênio amoniacal & $-55,9$ & 1,9 & 20,1 & 43,3 & 30,7 \\
Fósforo total & 36,0 & 25,0 & 39,6 & 37,9 & 82,0 \\
Coliformes termotolerantes & 98,3 & 93,1 & 82,3 & 95,9 & 99,99 \\
Escherichia coli & 98,3 & 94,0 & 89,6 & 97,7 & 99,999 \\
\hline
\end{tabular}

Os valores negativos na Tab. 1 indicam aumento da concentração do parâmetro dentro da unidade de tratamento, isto é, não houve remoção, e sim aumento da concentração do constituinte.

O RAC seguido do reator UASB foram os maiores responsáveis pela remoção da DBO. A eficiência do reator UASB foi de $86,5 \%$, sendo acima da encontrada por Campos et al. (2006), de $78 \%$, e a mesma relatada por Rodrigues et al. (2010), de $87 \%$.

As lagoas contribuíram na eficiência de remoção da DBO, sendo $53,4 \%$ para a LF e $50,8 \%$ para as lagoas de maturação em série, não se considerando a biomassa algal. Araújo et al. (2010) encontraram 41,7\% de eficiência na lagoa de maturação que precedia uma lagoa facultativa aerada, reator UASB e lagoa anaeróbia, tratando dejetos de suínos.

O comportamento da DQO foi semelhante ao da DBO, com eficiências de remoção de DQO de $81,9 \%$ no RAC e de $79 \%$ no reator UASB. Fernandes e Oliveira (2006), ao tratarem efluente de suinocultura com reator compartimentado operando com COV de 5,05 a $10,12 \mathrm{kgDQO} \mathrm{m}^{-}$ ${ }^{3} \cdot \mathrm{d}^{-1}$, conseguiram eficiência média de remoção de DQO de 71,1 a $87,5 \%$, operando com ensaios de 56, 28 e quatro horas. Já o reator UASB, posterior ao compartimentado, operando com COV de $2,83 \mathrm{kgDQO} \mathrm{m}^{-3} \cdot \mathrm{d}^{-1}$, obteve eficiência de remoção de DQO de $41,8 \%$, trabalhando com 13 , 6,5 e quatro horas.

A eficiência global de remoção de DQO do sistema foi de $96,9 \%$. O RAC teve uma boa 
remoção do material filtrado, ao retirar a maior parte do material biodegradável, restando para o reator UASB um material de mais difícil degradação.

As eficiências de remoção da lagoa facultativa e das lagoas de maturação foram de 14,2 e 3,6\%, respectivamente. Araújo et al. (2010) encontraram eficiências superiores na lagoa de maturação, de $52,4 \%$, e na lagoa facultativa aerada, de $61,8 \%$.

A relação SSV/SST no afluente e nos efluentes do RAC, UASB, LF, LM1, LM2 e LM3 corresponde, respectivamente, a 0,87, 0,85, 0,97, 0,99, 0,96, 0,99 e 0,99. Esses valores mostram a predominância de material orgânico nos sólidos suspensos dos efluentes de suinocultura, mesmo na água residuária tratada, sugerindo a presença de partículas de lodo composto por microrganismos ou mesmo sólidos suspensos do afluente estabilizado, os quais foram arrastados com o efluente. No caso das lagoas, os sólidos suspensos podem ser devido às algas que saíram com o efluente, como já relatado por Sperling (2002).

O RAC e o reator UASB apresentaram altas eficiências na remoção dos SST e SSV, sendo os responsáveis pela maior parte da eficiência global do sistema. Apesar de a maior parte ter sido removida nos reatores anaeróbios, a lagoa facultativa teve eficiência de $22,5 \%$ e $20,9 \%$ para SST e SSV, respectivamente. As lagoas de maturação apresentaram eficiências negativas devido à alta concentração algal, responsável pela maior parte dos sólidos suspensos.

A concentração $\mathrm{N}$-am. afluente foi de $202 \mathrm{mg} \mathrm{L}^{-1}$, sendo semelhante à encontrada por Duda e Oliveira (2009), com valores variando de 164 a $274 \mathrm{mg} \mathrm{L}^{-1}$. O RAC (315mg L $\left.\mathrm{L}^{-1}\right)$ apresentou concentração média maior que a do afluente, em razão do processo de amonificação, no qual o nitrogênio orgânico se converte em amônia. No reator UASB, a redução de amônia pode ter sido provocada, principalmente, pelo processo de sedimentação do nitrogênio orgânico.

As eficiências de remoção do $\mathrm{N}$-am. foram de $55,9,1,9,20,1$ e $43,3 \%$ para o RAC, UASB, LF e lagoas de maturação, respectivamente. A eficiência global do sistema foi de 30,7\%.
A grande variação do oxigênio dissolvido, com valores chegando a zero ou próximos deste no período da manhã e a $14 \mathrm{mg} \mathrm{L}^{-1}$ no período da tarde, é uma evidência de que deve estar acontecendo o processo de nitrificação nas horas mais quentes do dia, no qual a amônia é convertida a nitrito e deste a nitrato por bactérias aeróbias, e desnitrificação no período da noite, quando há presença de regiões anóxicas, em que o nitrato é convertido a nitrogênio gasoso, que escapa via atmosfera, permitindo a liberação do nitrogênio gasoso. Além destes mecanismos, pode-se supor que ocorreu a assimilação da amônia pelas algas, já que trabalhos recentes têm demonstrado que a volatilização da amônia não é uma via de remoção importante, mesmo em condições de $\mathrm{pH}$ e temperatura ideais (Camargo Valero e Mara, 2007; Camargo Valero et al., 2009a; Camargo Valero et al., 2009b).

Rodrigues et al. (2010) relataram eficiências de remoção de $-62,3,-30,1$, e $57 \%$ no sistema composto de decantador, reator UASB e lagoa de polimento. Já Duda e Oliveira (2009), com sistema composto por dois reatores anaeróbios operados em batelada sequencial seguidos de duas lagoas de polimento em série, observaram nas lagoas eficiência de remoção de amônia de 83 e $65 \%$, trabalhando com tempo de detenção hidráulico (TDH) de 33,2 e 25 dias, respectivamente.

O valor médio do afluente de fósforo foi de $100 \mathrm{mg} \mathrm{L}^{-1}$, sendo bem abaixo do encontrado por Rodrigues (2008), com Pt de 636 $\mathrm{mg} \mathrm{L}^{-1}$, ao trabalhar com dejetos da mesma suinocultura. Essa diferença se deve à utilização de dejetos peneirados neste trabalho. Ramires (2005) encontrou valores médios de $\mathrm{Pt}$ no afluente variando de 162 a $337 \mathrm{mg} \mathrm{L}^{-1}$.

As eficiências médias de remoção de fósforo total do RAC e do reator UASB foram de 36 e 25\%, respectivamente. Essas reduções são atribuídas basicamente ao processo de sedimentação dos sólidos, uma vez que os valores médios de pH 7,0 e 7,14 estão bem abaixo do valor mínimo para que ocorra a precipitação do fosfato.

A maior eficiência de remoção de fósforo total foi observada na lagoa facultativa $(39,6 \%)$, embora Bastos et al. (2003) tenham relatado que lagoas facultativas não conseguem eficiência 
maior que $35 \%$. Esse resultado, provavelmente, foi devido à assimilação pela biomassa de algas e bactérias e à precipitação, embora o pH $(7,90)$ não tenha se elevado o suficiente para uma remoção mais significativa por precipitação. Segundo Sperling (2002), seria necessário pH de, no mínimo, 9,0 para que esta ocorresse de forma significativa em lagoas. Medri (1997) encontrou valor semelhante, com remoção de $30 \%$ de Pt na lagoa facultativa, com $\mathrm{TDH}$ de 24 dias e $\mathrm{pH}$ médio de 7,8 .

As lagoas de maturação tiveram eficiência média de remoção de fósforo total de $37,9 \%$. As baixas eficiências dessas lagoas se devem aos baixos TDH e, provavelmente, ao grande decaimento das algas no fundo das lagoas, o que favorece a ressolubilização do fósforo, principalmente no período da noite, pelo aumento da camada anaeróbia. O sistema apresentou uma boa eficiência de remoção, $82 \%$, apesar de as unidades de forma isolada não terem realizado remoções significativas.

A eficiência média global do sistema para CT foi de $99,99 \%$, sendo o RAC responsável pela maior remoção, 98,3\%, provavelmente devido à sedimentação dos sólidos.

O sistema removeu $99,999 \%$ de E. coli, sendo novamente o RAC responsável pela maior remoção, com 2,00 unidades logarítmicas, devido à sedimentação. Medri (1997), ao estudar uma série de lagoas (duas anaeróbias, uma facultativa e uma de aguapé), que tratavam dejetos de suinocultura, encontrou maior eficiência de remoção de coliformes termotolerantes nas lagoas anaeróbias, de 99,8 e $99,0 \%$, e atribuiu esse resultado ao fato de uma grande parcela da concentração de coliformes afluente ter sido removida por sedimentação na primeira lagoa.

A lagoa facultativa obteve baixa remoção, com $82,3 \%$ e $89,6 \%$ de eficiência e 0,85 e 0,98 unidades logarítmicas removidas para CT e $E$. coli, respectivamente, pois, de acordo com Sperling (2002), lagoas facultativas devem apresentar remoçãoes superiores a $99 \%$. Rodrigues et al. (2009), ao trabalharem com lagoa facultativa após reator UASB, relataram eficiência de $95,11 \%$ e $95,34 \%$, com 1,31 e 1,33 unidades logarítmicas removidas de CT e coliformes termotolerantes, respectivamente. A baixa eficiência da LF, apesar do TDH de 23,7 dias, talvez possa ser explicada pela altura de $1,10 \mathrm{~m}$, a qual não favoreceu a penetração ideal de radiação ultravioleta, nem uma boa formação de algas. Araújo et al. (2010) conseguiram remoção de 2 unidades logarítmicas no sistema com lagoa facultativa aerada seguida de lagoa de maturação.

Apesar do bom desempenho do sistema, a eficiência das lagoas de maturação foi muito baixa na remoção de CT e E. coli, considerandose que eficiências altas na remoção de coliformes devem ser superiores a $99 \%$. O conjunto de lagoas de maturação apresentou eficiência de 95,9 e $97,7 \%$ com remoção de 1,40 e 1,70 unidades logarítmicas para CT e E. coli, respectivamente. Esses valores estão bem abaixo dos citados por Sperling (2002), em que lagoas de maturação devem atingir eficiências de remoção superiores a 99,9 ou 99,99\%. Mesmo com a altura de $0,40 \mathrm{~m}$, a eficiência foi muito baixa, provavelmente pela necessidade de um TDH maior, já que as lagoas de maturação M1, M2 e M3 trabalharam com TDH de 1,9 dia cada, o que estaria muito abaixo do valor mínimo de três dias citado por Marais (1974). Isso fez com que o pH das lagoas não estivesse alto o suficiente para uma elevada remoção de coliformes.

\section{CONCLUSÕES}

O sistema de tratamento constituído por reator anaeróbio compartimentado com reator UASB seguido de lagoas de polimento foi eficiente na remoção de matéria orgânica e sólidos, sendo que as lagoas, embora não tenham sido projetadas para este fim, também deram uma boa contribuição na remoção de matéria orgânica, apesar do crescimento de algas. As lagoas de pós-tratamento apresentaram alto desempenho na remoção de nutrientes, porém, quanto à remoção de coliformes, não foram eficientes.

\section{AGRADECIMENTOS}

À Fundação de Amparo à Pesquisa de Minas Gerais (Fapemig), pelo apoio financeiro, e à Universidade Federal de Minas Gerais. 


\section{REFERÊNCIAS}

APHA/AWWA/WEF. Standard Methods for the Examination of water and wastewater, 21. ed. Washington, D.C, 2005. 1600p.

ARAUJO, I.S.; COSTA, R.H.R.; FILHO, P.B. Utilização de lagoa facultativa aerada e lagoa de maturação em série para tratamento de dejetos suínos. In: SIMPÓSIO INTERNACIONAL DE QUALIDADE AMBIENTAL, 7., 2010, Porto Alegre, RS. Anais... Porto Alegre: [s.n.] 2010. (Resumo).

BASTOS, R.K.X. Utilização de Esgotos tratados em fertirrigação, hidroponia e piscicultura. Viçosa: PROSAB, 2003. 267p.

CAMARGO VALERO, M.A.; MARA, D.D. Nitrogen removal via ammonia volatilization in maturation ponds. Water Sci. and Technol., v.55, p.87-92, 2007.

CAMARGO VALERO, M.A.; MARA, D.D.; NEWTON, R.J. Nitrogen removal in maturation WSP ponds via biological uptake and sedimentation of dead biomass. In: IWA SPECIALIST GROUP CONFERENCE ON WASTE STABILIZATION PONDS, 8., 2009. Belo Horizonte, Anais... Belo Horizonte: [s.n.] 2009a. (Resumo).

CAMARGO VALERO, M.A.; READ, L.F.; MARA, D.D. et al. Nitrification-denitrification in WSP: a mechanism for permanent nitrogen removal in maturation ponds. In: IWA SPECIALIST GROUP CONFERENCE ON WASTE STABILIZATION PONDS, 8., 2009. Belo Horizonte, Anais... Belo Horizonte: [s.n.] 2009b. (Resumo).

CAMPOS, C.M.M.; CARMO, F.R.; BOTELHO, C.G.; COSTA, C.C. Desenvolvimento e operação de reator anaeróbio de manta de lodo (UASB) no tratamento dos efluentes da suinocultura em escala laboratorial. Ciências Agrotécnicas, v.30, p.140-147, 2006.

CARMO, F.R.; CAMPOS, C.M.M.; BOTELHO, C.G.; COSTA, C.C. Uso de lagoa aerada facultativa como polimento do reator anaeróbio de manta de lodo UASB no tratamento de dejetos de suínos em escala laboratorial. Cienc. Agrot., v.28, p.600-607, 2004.
DUDA, R.M.; OLIVEIRA, R.A. Reatores anaeróbios operados em batelada sequencial seguidos de lagoas de polimento para o tratamento de águas residuárias de suinocultura. Parte II: remoção de nutrientes e coliformes. Eng. Agríc., v.29, p.135-145, 2009.

FERNANDES, G.F.R.; OLIVEIRA, R.A. Desempenho de processo anaeróbio em dois estágios (reator compartimentado seguido de reator UASB) para tratamento de águas residuárias de suinocultura. Eng. Agríc., v.26, p.243-256, 2006.

ISHIZUKA, M.M. A biotecnologia no tratamento de dejetos de suínos. Disponível em: <http: //www.cnpsa.embrapa.br>. Acessado em: 12 dez. 2011.

MARAIS, G.V.R. Faecal bacterial kinetics in stabilization ponds. J. of the Env. Engin. Division, ASCE. v.100, p.119-139, 1974.

MEDRI, W. Modelagem e otimização de sistemas de lagoas de estabilização para tratamento de dejetos de suínos. 1997. 206f. Tese (Doutorado em Engenharia da Produção). Universidade Federal de Santa Catarina - UFSC, Florianópolis.

PALHARES, J.C.P.; CALIJURI, M.C. Impacto de sistemas de produção suínicola na qualidade dos recursos hídricos. Concórdia: Embrapa Suínos e Aves, 2006. 2p.

RAMIRES, R.D. Produção de metano $e$ remoção de matéria orgânica, nutrientes $e$ microrganismos patogênicos em reatores anaeróbios de fluxo ascendente com manta de lodo (USAB) em dois estágios tratando águas residuárias de suinocultura. 2005. 136f. Dissertação (Mestrado em Microbiologia Agropecuária). Universidade Estadual Paulista, Jaboticabal, SP.

RODRIGUES, L.S. Concepção e avaliação de sistema de tratamento com reator anaeróbio de manta de lodo (UASB) e lagoa de polimento para águas residuárias de suinocultura. 2008. 151f. Tese (Doutorado em Ciência Animal). Universidade Federal de Minas Gerais. Belo Horizonte, MG. 
RODRIGUES, L.S.; SILVA, I.J; SANTOS, R.L.H.; GOULART, D.B. et al. Avaliação de desempenho de lagoa de polimento para póstratamento de reator anaeróbio de manta de lodo (UASB) no tratamento de águas residuárias de suinocultura. Arq. Bras. Med. Vet. e Zootec., v.61, p.1428-1433, 2009.
RODRIGUES, L.S.; SILVA, I.J.; ZOCRATO, M.C.O.; PAPA, D.N. et al. Avaliação de desempenho de reator UASB no tratamento de águas residuárias de suinocultura. Rev. Bras. Eng. Agrícola e Ambiental, v.14, p.94-100, 2010.

SPERLING, M. Von. Lagoas de Estabilização. Princípios do Tratamento Biológico de Águas Residuárias, v.3. 2.ed. Belo Horizonte: DESA UFMG, 2002. 